\title{
The Journey Experience of Visually Impaired People on Public Transport in
}

\section{London}

\begin{abstract}
The use of public transport is critical for Visually Impaired People (VIP) to be independent and have access to out-of-home activities. Despite government policies promoting accessible transport for everyone, the needs of VIP are not well addressed, and journeys can be very difficult to negotiate. Journey requirements can often differ from those of other categories of people on the disability spectrum. Therefore, the aim of this research is to evaluate the journey experience of VIP using public transport. Semi-structured interviews conducted in London are used. The results show that limited access to information, inconsistencies in infrastructure and poor availability of staff assistance are the major concerns. Concessionary travel, on the other hand, encourages VIP to make more trips and hence has a positive effect on well-being. The findings suggest that more specific policies should be introduced to cater to the special needs of particular disabilities rather than generalising the types of aids available. It is also concluded that the journey experience of VIP is closely related to an individual's independence and hence inclusion in society.
\end{abstract}

\section{Keywords}

Public transport; Transport policy; Travel behaviour; Visually impaired people; Journey experience; Well-being.

\section{Highlights}

- The lack of a single integrated means for accessing travel information is an obstacle to making trips for VIP.

- VIP share their experiences of accessing staff assistance using public transport in London and highlight its importance to their journey experience.

- Audio information is particularly important when information cannot be accessed through visual sources.

- A Freedom Pass encourages VIP to engage in more social interactions by removing the cost barrier to travelling in London. 


\section{Introduction}

In the UK alone, there are more than two million visually impaired people (VIP), accounting for a significant proportion of the population (RNIB, 2018). The loss of vision makes travel very difficult, particularly in terms of loss of independence. VIP may find themselves relying on being driven by others or taking public transport (American Foundation for the Blind, 2015; Clery et al., 2017). The availability of appropriate public transport is therefore crucial for many VIP to be able to access opportunities. Journey experiences are important for all public transport users (Hine and Scott, 2000). We therefore examine the journey experiences of VIP in London, which provides a good basis for the research in view of the extensive public transport system and high public transport mode share - more than $45 \%$ of daily trips are made on public transport (TfL, 2016). However, simply having an extensive public transport network does not necessarily mean that everyone can easily use it and/or obtain equal benefits (Cao and Hickman, 2019a, 2019b, 2020). Currently, VIP tend to make a higher proportion of trips by taxi, as this offers a more customised means of travel. Also this may suppress overall trip rates amongst VIP. The Freedom Pass is one of the incentives used to encourage VIP to make trips using public transport, as it entitles the holder to free travel on the Transport for London (TfL) network, thus removing the cost barrier to travelling. Nonetheless, there are other features of the journey experience beyond this (Carreira et al., 2014; Hickman et al., 2015).

Most countries and cities have some form of policy objectives designed to build a more equal society, at least in terms of opportunity, but perhaps also in terms of outcome. A key element here is the transport system and its use by different population groups, including facilitating equal access for physically disabled people relative to nondisabled people. When the terms "access" and "disabled people" are used in conjunction, common perceptions tend to focus on the provision of barrier-free access for wheelchair users. This group is of course important, but there are other types of disability, including those who are visually impaired.

Since the Disability Discrimination Act 1995, it has not been lawful to discriminate against people in relation to the provision of transport (Disability Discrimination Act, 1995). In 1998, the UK government's White Paper on Transport, entitled "Better for Everyone", emphasised the role of transport in shaping an inclusive environment. Various policies have been established regarding the provision of accessible transport, such as improving the design of interchange stations to cater to the needs of disabled passengers (DfT, 1998). The Disability Discrimination Act 2005 introduced provisions that had an impact on public transport providers, particularly in terms of the rail sectors (Disability Discrimination Act, 2005). It was also stated in the Equality Act 2010 that transport must be accessible for all (Equality Act, 2010). However, it appears that few of these policies and regulations are specifically aimed at the needs of VIP. Still public transport is far from accessible for all (GLA, 2018). In terms of the social model of disability, it highlights that being able to see is very important (Oliver, 1983). Visual impairment is particularly poorly considered on the transport system even where adaptations have been made for other disabilities. VIP may not be able to benefit from the general improvements in accessibility that have been implemented in the past two decades. For example, although step-free access has been introduced across the TfL 
network, VIP with guide dogs may not be able to make use of the facilities as the guide dogs have often not been trained in using escalators and lifts.

This paper examines the journey experience of VIP, particularly those living in London in the current era of mass availability of information technology. It seeks to provide evidence on journey experiences that are under researched. The journey experiences of VIP using public transport are explored in three ways: 1) to identify the barriers facing VIP in using public transport; 2) to explore improvements in accessible travel support from a user perspective; and 3) to understand the meaning and implications of concessionary travel for VIP. In-depth, semi-structured interviews were conducted to understand the needs and expectations of VIP, involving a reflective exercise on their previous experience of public transport. Common issues are highlighted and their relevance to the journey experience are analysed.

The remainder of the paper is structured as follows: section 2 examines the existing knowledge concerning public transport and VIP, as well as their journey experiences and the relevant transport context. Section 3 introduces the methodology, including the research framework of the journey cycle, which helps us to understand the journey experience of a disabled passenger, and the use of the qualitative approach for data collection. Section 4 discusses the research findings. Finally, section 5 presents the conclusions and outlines the policy implications of the research.

\section{Literature Review}

Related studies on the journey experiences of VIP have been conducted in the USA (Marston, Golledge and Costanzo, 1997), Ireland (Gallagher et al., 2011; Casey, Brady and Guerin, 2013), Scotland (Hine and Scott, 2001; Montarzino et al., 2007) and Hong Kong (HKSWGU, 2016). The context of London is different, in terms of extent of the public transport system, the age of infrastructure, the volume of passengers, the cultural context, and other issues. Hence it is useful to broaden the evidence base on VIP journey experiences. Moreover, improved assistive technologies and the availability of smart technology have enhanced the journey experience of VIP, and those improvements were not reported in previous research. For instance, much of the existing literature cites accessing information in printed format as a common practice among VIP, but does not take into account the wider availability of information on the Internet. Although research has been conducted into accessible transport in the UK, covering a wide range of disabilities, VIP participants are often overlooked. Accessible transport often correlates to step-free access, which is not the major challenge for most VIP. Instead, they are more likely to be concerned with consistency of infrastructure and availability of assistance. Hence, there is a knowledge gap in terms of understanding the specific needs of VIP and ultimately improving their journey experience that will be discussed in the following sections.

\subsection{The importance of public transport to VIP}

A lack of access to public transport poses a barrier in terms of employment opportunities for VIP of working age (Marston and Golledge, 1998). The sight loss of VIP creates different needs for their use of public transport than individuals with other disabilities (Clery et al., 2017), hence their requirements for using public transport can be very specific and different to other disability groups. Public transport is often the only option for VIP in making independent trips (American Foundation for the Blind, 
2015), and hence plays a vital role in providing VIP with accessibility.

VIP are regarded as a subgroup within the "transport disadvantaged" and might experience social disadvantage and exclusion due to their limited choices for independent travel among existing transport modes (Lucas, 2012). They are physically excluded from driving a car (Church et al., 2000), often resulting in high unemployment among VIP (Marston and Golledge, 1998; Goertz et al., 2010; Joseph and Robinson, 2012; Coffey et al., 2014). Furthermore, limitations to transport constitute barriers for VIP in accessing opportunities and social networks (Kenyon, Lyons and Rafferty, 2002; RNIB, 2014). Restricted access to travel information is a common barrier to independent travel and other everyday activities for VIP (Marston and Golledge, 2003; TRL Limited, 2004). Hence VIP must overcome significant obstacles to their use of transport for access to activities and opportunities. Banister and Bowling (2004) defined engagement in social activities, and the availability of community and transport facilities within a person's neighbourhood as two of the building blocks for a good quality of life among older people. Transport is an enabling factor in this physical participation. Furthermore, transport policy and transport systems shape the well-being of society by reducing access barriers and facilitating employment, relationships and health (Currie et al, 2009; Delbosc, 2012). Ultimately, the availability of good public transport services for VIP is critical to well-being and quality of life.

\subsection{The public transport experience of disabled passengers}

Initially, pre-trip planning is a key component of the public transport journey (Hine and Scott, 2000; Wardman, Hine and Stradling, 2001; Andre et al., 2007). Route choices are affected by information reliability and availability, as well as by convenience and comfort (Andre et al., 2007). Gaining information prior to a journey is a problem for VIP, because most information is printed (Casey, Brady and Guerin, 2013); however, recent advances in online material have helped here. A lack of usable information can inject a negative aspect into the overall experience and indeed prevent a journey from being made.

Moreover, travel behaviour among VIP is likely to be affected by the availability of accessible travel support. Statistics produced by the Disabled Persons Transport Advisory Committee suggest that railway transport is the least accessible, thus leading to a lower use rate for that mode by disabled passengers (Jones and Jain, 2006). Pavey et al. (2009) found that VIP prefer buses to trains in the UK. However, a recent survey in Hong Kong by Hong Kong Social Workers General Union (HKSWGU) (2016) produced contrasting findings, stating that railway travel was preferred there by VIP because of the availability of information and assistance. There are contextual differences, but this may also apply to the situation in London where stations are staffed.

Furthermore, bus travel for VIP includes various difficulties, such as finding the correct bus, and this is particularly problematic when multiple buses are approaching the stop (RNIB, 2012; White, 2013; Hara et al., 2015). The mix of fleets deployed also makes it difficult for VIP to identify the characteristics of a bus (Markiewicz and Skomorowski, 2010; Casey, Brady and Guerin, 2013). In addition, VIP find it difficult to locate the boarding point for buses (Golledge and Marston, 1999; Markiewicz and Skomorowski, 2010). A related factor is the reported unhelpful attitude of some drivers in assisting VIP when they are providing information about the route (Hine and Mitchell, 2001). Hence, bus journeys may be less appealing to VIP. 
Regarding railway travel, little research has investigated the challenges facing VIP in finding the correct service. Jones and Jain (2006) revealed that infrastructure issues within a station, such as handrails, stairs and uneven floors, pose obstacles to VIP when they travel. Cook (2014) compared the "turn-up-and-go" staff assistance programme for the London Underground with the pre-book-only assistance available for national rail services. Some VIP may need to get assistance from staff, which forms part of their journey experience. Only a few studies have considered the satisfaction levels of VIP with staff assistance on public transport. VIP appreciate being able to get settled on a train before other passengers board, assisted if necessary by staff (RICA, 2015).

Apart from identifying the correct bus service, VIP generally do not encounter difficulties in physically boarding the vehicle (Golledge, Marston and Costanzo, 1997). However, there are contrasting views on the issue of finding a seat. Some individuals are happy to stand during the ride (Golledge, Marston and Costanzo, 1997), while others describe finding a seat as a challenge on buses with different interior designs (Gallagher et al., 2011) or at peak times. However, there are more challenges for VIP in boarding a train, including automatic doors and the platform gap (Gallagher et al., 2011). Indeed, the gap between the train and platform causes anxiety among rail users in general (Cheng, 2010). Hence, VIP, who cannot see the gap, are likely to experience an even greater fear.

Access to information about the time and place to disembark is restricted (Gallagher et al., 2011), so VIP usually have to depend on sighted people to inform them when they are approaching a stop (Casey, Brady and Guerin, 2013), or make use of the Global Positioning System (GPS) on their mobile phones (Gonzalez et al., 2010). An audio announcement is critical in helping VIP prepare to exit the vehicle at the right place (Golledge, Marston and Costanzo, 1997; ECMT, 2006; RNIB Cymru, 2014; Smith, 2014). Audio announcements serve as the information source for VIP and are an important component of their journey, so their travel becomes especially stressful when the audio system malfunctions (UTTP, 2016). Satisfaction with public transport journeys is closely related to the information available to disabled people (Verbich and El-Geneidy, 2016).

Another challenge for VIP is to exit the vehicle in time (Golledge, Marston and Costanzo, 1997). They may not be able to see obstacles around them when they attempt to leave the carriage, and because of the often short waiting time at each station or stop, they have to reach the door quickly.

Hine and Scott (2000) identified transport interchanges as a factor affecting the journey experience of public transport users. Stradling et al.'s (2007) study on journey experiences by bus revealed that safety and unexpected interactions with other passengers are two factors affecting the journey experience. Critical incidents also have an impact on how a person considers future journeys (Edvardsson, 1998). Most VIP believe that improvements in public transport would influence their lives positively (DPTAC, 2006). Walking time, reliability, and the number and frequency of available services all contribute to service quality (Eboli and Mazzulla, 2008; TfL, 2015). The attitudes and behaviour of staff and other passengers also influence the journey experience of disabled passengers (TfL, 2012). However, VIP are likely to be especially concerned with accessibility supports, such as priority seating, staff assistance and 
journey planning support, because they have more stringent considerations than sighted passengers do.

\subsection{Availability of assistive technology to VIP}

Assistive technology refers to any system, services, appliances or devices that could be used to help disabled people with their daily life by removing some barriers to activities (Hersh, 2010). Assistive technology for VIP was first introduced in the 1960s to address mobility issues and the transmission of information, two of the major obstacles to independent living for most VIP (Marion and Michael, 2008). An understanding of the availability of assistive technology to VIP could therefore help to tailor current technologies to the journey experience of VIP.

Mobility tools are one of the common assistive tools available to VIP. According to Rizzo et al (2018), a long cane is the most commonly used mobility tool among VIP and is widely regarded as an effective aid. A guide dog is another familiar option for VIP, not only serving the purpose of a mobility tool, but also improving the social wellbeing of VIP by acting as a bridge between the VIP and the sighted world (Warnath and Seyfarth, 1982).

GPS was developed into assistive technology for VIP for orientation purposes and as a navigation aid for VIP (Balachandran, Cecelja and Ptasinski, 2003). GPS can also be integrated into other devices to help VIP find their way; for instance, a GPS-based voice alert system was developed to notify VIP of obstacles nearby (Gulati, 2011).

With technological advancements over the past decade, smart technology has become more readily available to VIP, and has had a significant impact on their lives (Bhowmick and Shyamanta, 2017). Mobile phone applications such as Blind Square and SeeingAssistant-Move were developed as personal navigation alongside existing mobility tools, such as guide dogs and long canes, to provide integrated mobility aids for VIP (IET and ITS-UK, 2015). Screen reading technologies also transform textual information into an audible form for VIP, thus improving their access to information (Azenkot and Lee, 2013).

\subsection{Transport policies and transport systems}

People with disabilities make up a heterogeneous group with differing transport needs (Gant, 1992; Cook, 2014). Hence, it is important to have specific policies that facilitate travel according to different requirements, including reducing the financial barriers for VIP when they use conventional transport. Transport policies should integrate the planning of daily transport in ways that benefit all people (Hallgrimsdottir et al., 2016). There has to be a much greater focus on including all requirements in the design of transport systems - many issues tend to be overlooked for particular disability groups such as VIP.

The Freedom Pass (FP), which entitles disabled people to free travel on public transport in London, exemplifies a targeted intervention (London Councils, 2018a). Concessionary travel is designed to increase public transport usage, improve access to activities and reduce exclusion for the disadvantaged (Mackett, 2014), but research on its impact on VIP's trips is lacking. Metz (2003) and Mackett (2013) found that 
concessionary fares made travelling affordable and facilitated more trips for older people (Metz, 2003; Mackett, 2013, Johnson et al., 2017, Wong et al., 2018). However, Schmocker et al. (2005) claim that FP holders tend to make fewer trips than nondisabled people due to their restricted mobility, hence perhaps concessionary travel alone is not enough. Indeed, some VIP consider themselves physically mobile despite their loss of sight. Hence, it is insightful to examine how the FP has impacted on their travel patterns.

Furthermore, concessionary fares can bring about wider psychological impacts. For older people, they represent a symbolic entitlement to the free use of public transport, perhaps awarded in recognition of their contribution to society through a working life (Jones et al., 2013). Quality of life, public health and social inclusion are also enhanced through concessionary bus travel (Mackett, 2013). However, many studies focus on older people, whereas the FP may bring other benefits to VIP, and this research therefore explores those as well.

In summary, much of the existing literature covers general findings about disabled people and is limited to particular contexts. The importance of public transport to VIP is applicable to all contexts. The journey experience of disabled passengers varies across contexts, depending on the travel pattern and extensiveness of the public transport network. Understanding the journey experience of VIP could also help to tailor assistive technologies more effectively to the needs of VIP. Finally, transport policies play a vital role in addressing the needs of VIP. This study specifically examines the journey experience of VIP on public transport in the context of London.

\section{Methodology}

\subsection{Research framework}

The concept of the journey sequence is useful for understanding the journey experience of disabled passengers, because it breaks a trip into different components. All of these can represent a difficult point in a journey, and one weak link can mean a journey is not made or is uncomfortable. The concept of journey cycle was used by Soltani et al. (2012) to investigate the challenges faced by disabled passengers at transport terminals. We have adapted the cycle into a sequence of activities as follows (see Figure 1) to fit the London context and the actual experience of VIP on public transport.

"Buying tickets", which in earlier studies was located between "Arriving at station/stop" and "Finding the correct service", has been removed for two reasons. It is assumed that most VIP possess a FP, which entitles them to free travel on most public transport in London. In addition, TfL encourages the use of pay-as-you-go on public transport, via a Contactless Card or an Oyster Card, because this offers value, flexibility and convenience (TfL, 2018b). Hence, it is unlikely that passengers will have to buy single tickets for National Rail journeys across London. Furthermore, "Journey on board" has been added between "Boarding the chosen mode of transport" and "Getting to desired destination". This step concerns the interior environment of the vehicle and how the person feels during the ride. For instance, difficulties associated with finding a seat are discussed. This component was not included in Soltani et al.'s (2012) study which focused on accessibility at the transport terminal. Because journeys made by VIP 
consist of both a node and route, the component has been added accordingly.

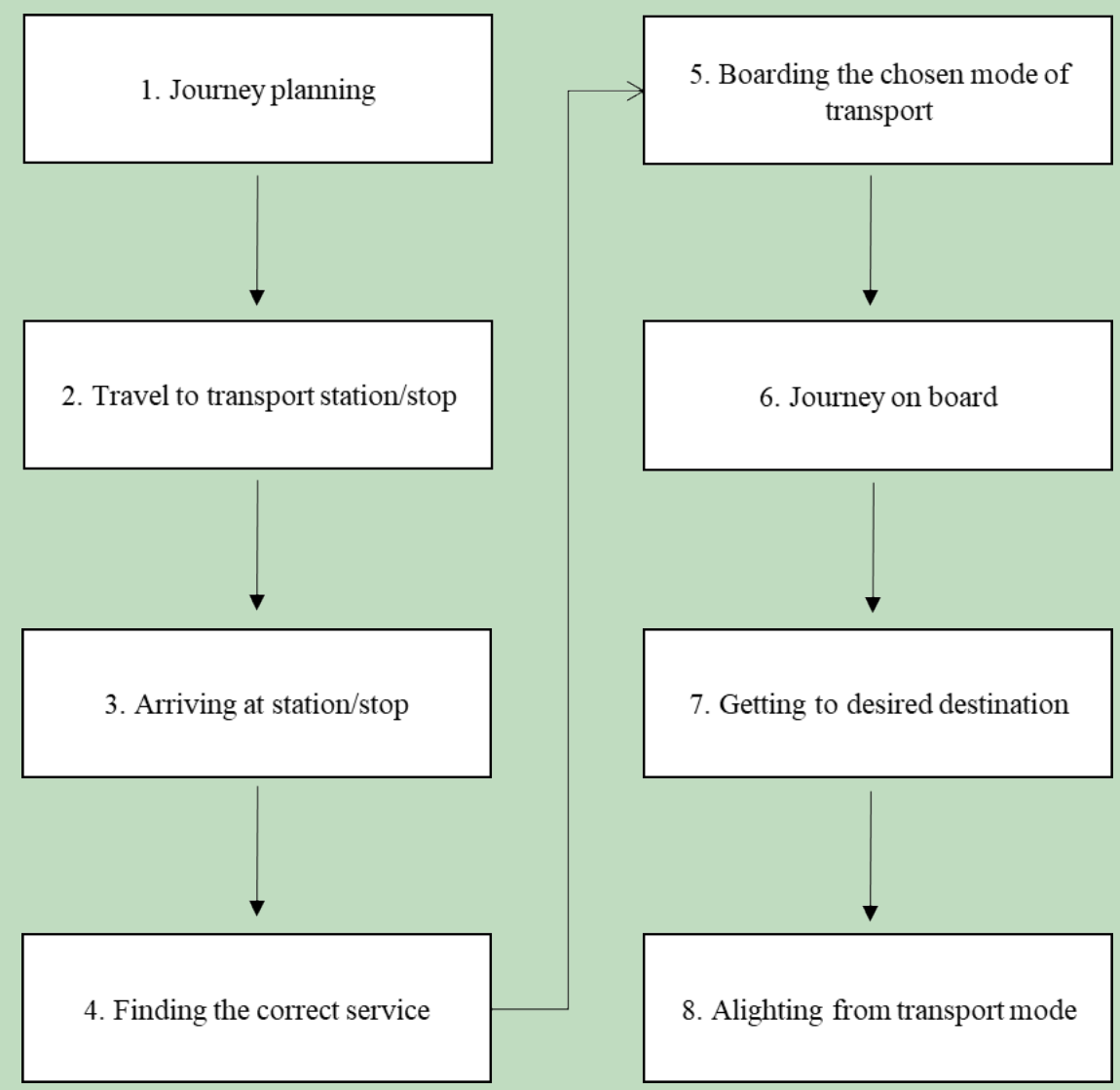

Figure 1. Research framework for journey sequence on public transport for VIP (Source: Authors, adapted from Lafratta, 2008 in Soltani et al., 2012)

\subsection{Qualitative semi-structured interviews}

A qualitative approach is used in the study, using semi-structured interviews with VIP. This approach has been adopted by previous studies with regard to the journey experiences of VIP (Hine and Mitchell, 2001; Gallagher et al., 2011; Casey, Brady and Guerin, 2013; HKSWGU, 2016). The interviews allow a rich discussion and understanding of varied journey experiences. The semi-structured nature enables data reproducibility by having a similar set of questions for all interviewees. The interviews also address more specific issues as the discussion develops and allow a more detailed understanding to be developed (Bryman, 2008). Follow-up questions could be raised with reference to a response in order to better understand the journey experiences of the VIP in the study.

23 interviewees were recruited through snowball sampling by asking the respondents to refer more participants, with the analysis carried out between May and July 2018. A list of topics covered in the semi-structured interview can be found in Appendix 1. These were derived by using the issues evident in the existing literature, modified according to our understanding of the London context. The snowball method was useful in recruiting the hard-to-reach groups (Sammer et al., 2012), including the wide range of VIP in London, with differing ages, degrees of sight loss, mobility tools and genders. By including a variety of different backgrounds and characteristics among the 
interviewees, it was hoped that people from different walks of life could be included. This would represent the differing experiences of VIP. The interview material was analysed using NVivo 11. All the interviews were carried out in a face-to-face setting and lasted between 45 and 90 minutes. The aforementioned data are summarised in Table 1. We were able to collect a varied sample in terms of age, gender and degree of sight loss. The qualitative analysis is exploratory rather than definitive.

Table 1 Profiles of participants

\begin{tabular}{|c|c|c|c|c|}
\hline Code & Age Group & Degree of Sight Loss & Mobility Tool & Gender \\
\hline A & $46-60$ & Severely Sight Impaired $^{1}$ & Symbol Cane $^{2}$ & Male \\
\hline B & Below 30 & Completely Blind & Long Cane & Female \\
\hline $\mathrm{C}$ & Below 30 & Partially Sighted $^{3}$ & Symbol Cane & Female \\
\hline $\mathrm{D}$ & $31-45$ & Completely Blind & Guide dog & Male \\
\hline $\mathrm{E}$ & Above 60 & Severely Sight Impaired & Guide dog & Male \\
\hline $\mathrm{F}$ & $46-60$ & Severely Sight Impaired & Guide dog & Female \\
\hline G & $31-45$ & Severely Sight Impaired & Long Cane & Female \\
\hline $\mathrm{H}$ & $46-60$ & Completely Blind & Guide dog & Male \\
\hline I & Below 30 & Severely Sight Impaired & Guide dog & Female \\
\hline $\mathrm{J}$ & $31-45$ & Partially Sighted & Symbol Cane & Female \\
\hline $\mathrm{K}$ & Above 60 & Completely Blind & Long Cane & Male \\
\hline $\mathrm{L}$ & $31-45$ & Severely Sight Impaired & Long Cane & Female \\
\hline M & $31-45$ & Completely Blind & Long Cane & Male \\
\hline $\mathrm{N}$ & Above 60 & Partially Sighted & Symbol Cane & Female \\
\hline $\mathrm{O}$ & $31-45$ & Partially Sighted & No & Male \\
\hline $\mathrm{P}$ & $31-45$ & Completely Blind & Long Cane & Male \\
\hline Q & $31-45$ & Severely Sight Impaired & Guide dog & Female \\
\hline $\mathrm{R}$ & $46-60$ & Severely Sight Impaired & Long Cane & Female \\
\hline $\mathrm{S}$ & $31-45$ & Completely Blind & Long Cane & Male \\
\hline $\mathrm{T}$ & $31-45$ & Completely Blind & Long Cane & Female \\
\hline $\mathrm{U}$ & $31-45$ & Severely Sight Impaired & Long Cane & Male \\
\hline V & $31-45$ & Completely Blind & Long Cane & Female \\
\hline $\mathrm{W}$ & Above 60 & Severely Sight Impaired & Long Cane & Male \\
\hline
\end{tabular}

The interview embodied a systematic approach for reviewing accessible transport provision in London, covering the issues drawn from findings in the literature. The first and second objectives focused on barriers and improvements, and were approached via the adapted journey sequence concept. Questions followed the flow of the journey sequence, enabling participants to reflect chronologically on their own journey experience. This allowed them to review the barriers they had encountered and identify improvements that could boost their experience. In addition, interviewees were asked

\footnotetext{
${ }^{1}$ Severely sight impaired is defined as gross visual field restriction, meaning that a person is unable to see within 3 metres.

${ }^{2}$ A symbol cane highlights disability to other people, but cannot be used as a walking stick nor to detect obstacles on the ground.

${ }^{3}$ Partially sighted is defined as having some types of visual problem that make it difficult to recognise people in the street, to drive and to watch television.
} 
to give their opinions about and knowledge of the pamphlet "Accessible travel in London", published by TfL. This helped build an understanding of the barriers they face in accessing information. The interview also examined the impacts and implications of the FP in shaping the use of public transport for VIP. Whereas previous literature had focused on the impact on older users of public transport (Mackett, 2013), new findings were anticipated for VIP, because they had different requirements and conditions in terms of their access to transport.

There are some limitations to this research approach. First, as the profiles of the interviewees show, all had experience of travelling alone on public transport, and therefore might not represent less independent individuals. In addition, most of the interviews were arranged via email and/or telephone, which meant the respondents had access to this technology. Hence, again, their experience may not fully reflect the challenges faced by less independent individuals or those who face major barriers in accessing information. Nonetheless, these participants were able to represent a good range of VIP in the city and provide valuable insights.

A risk assessment was conducted, and an ethical approval form submitted and approved by UCL's ethics committee. Verbal consent was obtained from the participants at the beginning of the interviews. Saleh (2004) suggested that recorded audio consent could offer an alternative to written consent for VIP without reducing validity. This was also in line with the Disability Discrimination Act, which requires that appropriate changes be made to suit the needs of disabled participants (ibid.).

\section{Research Findings and Discussion}

The findings are grouped into the following categories: barriers to accessing information; consistency of layout; the availability of real time information; audio announcements and staff assistance; and the provision of concessionary travel.

\subsection{Barriers to accessing information}

During the interviews it was found that journey planning by VIP nowadays is mostly done digitally, via the Internet or Apps. None of the interviewees mentioned traditional methods, such as consulting timetables or physically visiting the station in advance to gather information for their journeys. A few mentioned family and friends as a source of information. These findings are contrary to the traditional methods outlined by Golledge, Marston and Costanzo (1997) and can be explained by the current wider availability of online information due to technological advancement. The findings also reflect the desire of VIP to be independent in planning their journeys by using online resources instead of seeking help from others, and the data reveal their efforts to do so. This shows the importance of having appropriate online tools for VIP.

Despite the ease of consulting online information, journey planning remained stressful for the interviewees, as described below:

"A lot of planning is involved. I have all types of Apps on my phone for planning the journey."

(Interviewee C, Female, 7/6/2018) 
"I use TfL journey planner a lot, but it does not give clear walking directions. Hence I have to use GPS on my phone to find my way."

(Interviewee D, Male, 7/6/2018)

Most interviewees mentioned they used the TfL journey planner as their source of journey information because it is linked to real-time service updates. However, it is only available in a web version, so it cannot be used with GPS for navigation. It provides information about routes, but leaves out the first and last mile, so VIP must consult additional sources to fill this gap. This is not an ideal experience for VIP, who have to expend greater effort than sighted people in acquiring information.

Moreover, VIP lack access to policy updates and information about available assistance. More than half of the interviewees had not heard of the Accessible Travel Guide by TfL. This printed pamphlet, which is available at stations, is not readily accessible to them due to its small size. In addition, a few staff at some of the smaller Underground stations had not heard of the guide either, and would therefore not be able to offer it to VIP if needed or requested. Although much information can be found online, it is difficult for VIP to get the essential information they need. Indeed, VIP commonly experience access issues to online resources, even if they have access to the Internet.

“Websites are really complicated to access so people just don't get to know the information."

(Interviewee T, Female, 27/6/2018)

"Some are inaccessible because they're in PDF."

(Interviewee B, Female, 30/5/2018)

"Not all information can be found at one place. Sometimes you need to do a bit of research to find out information, which takes time."

(Interviewee P, Male, 20/6/2018)

As a consequence of not being able to access all the information available, VIP can miss useful aids. More than half of the interviewees had not heard of the travel mentoring scheme offered by TfL, which a charity worker described as "very useful mobility assistance and training". Some interviewees asked for more details and expressed an interest in participating.

"I try to tell others about the scheme. It is the vulnerable ones who cannot get access to information."

(Interviewee J, Female, 13/6/2018)

Non-governmental organisations and charities have been the major sources of information and policy updates for most VIP. Hence, how much the VIP know depends on how the messages are channelled through their sources. Although VIP can get travel updates by subscribing to TfL accessibility news, only a few mentioned this as their source of information.

"There are not lots of announcements on policies. I only find out when there's been a negative impact."

(Interviewee I, Female, 13/6/2018) 
"Very often I rely on a third party to get the information. TfL cannot provide accessible travel information in an easy to consume way."

(Interviewee H, Male, 13/6/2018)

"It is not publicised as much as it should be."

(Interviewee K, Male, 14/6/2018)

All of these comments reflect a failing in terms of delivering the most up-to-date information to VIP, and they are often left uninformed when new policies or assistance become available that could improve their journey experience.

\subsection{Consistency}

Consistency in layout and design across the entire transport network is important to ensure that VIP can move around safely and confidently as they use their mental maps to navigate their journeys (Quinones et al., 2011). The current lack of consistency in the layout of the network is a barrier to disabled people that affects whether or not they have a smooth journey on public transport (Aarhaug and Elvebakk, 2015).

The consistent use of tactile paving is a critical safety need for VIP, because its presence warns them they are approaching the platform edge. The importance of tactile paving (Jones and Jain, 2006) remains crucial now, more than a decade later, because the interviewees indicated that railway stations in London, particularly National Rail stations, lack such paving. Such oversights pose safety threats to VIP, who consider tactile paving to be necessary and call for it to be installed on all platforms as soon as possible.

"Tactile paving should be at every platform - I actually fell onto the tracks with my guide dog because there was no tactile paving."

(Interviewee D, Male, 7/6/2018)

Another safety concern arising from the need for consistency involves the interior design of buses. For environmental and operational reasons, there are different bus fleets with different interior layouts. That inconsistency makes it challenging and confusing for VIP to navigate within the vehicle to find a seat or a place to stand. Buses may have single, double or triple doors, and that can confuse VIP about where to board and alight. Different locations for priority seating pose another challenge for VIP, who have no idea where such seats are before boarding (Figures 2 and 3). Often it is difficult for VIP to locate a safety handrail to hold onto before the bus departs. When passengers feel insecure and unsafe, it diminishes their journey experience. 


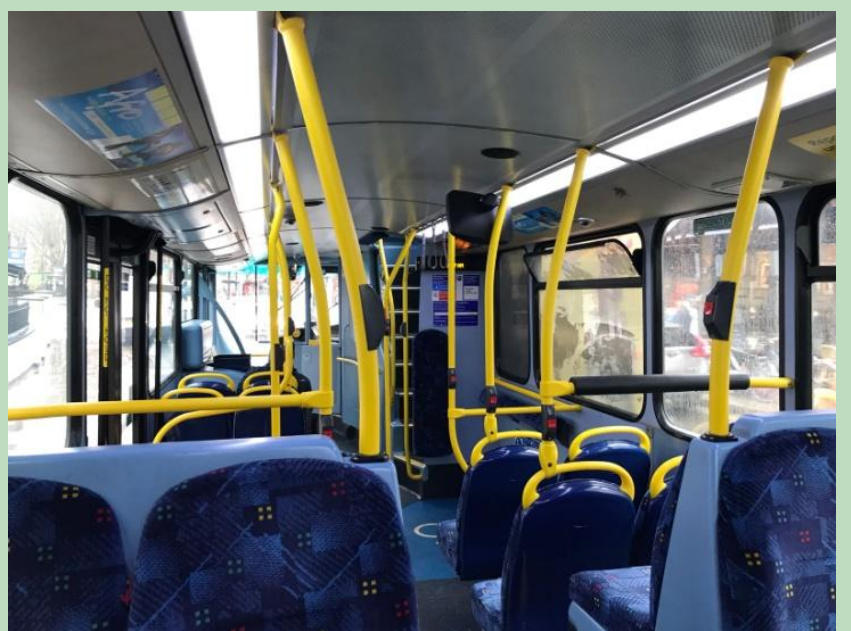

Figure 2. Interior design of Volvo B7TL (Source: Authors)

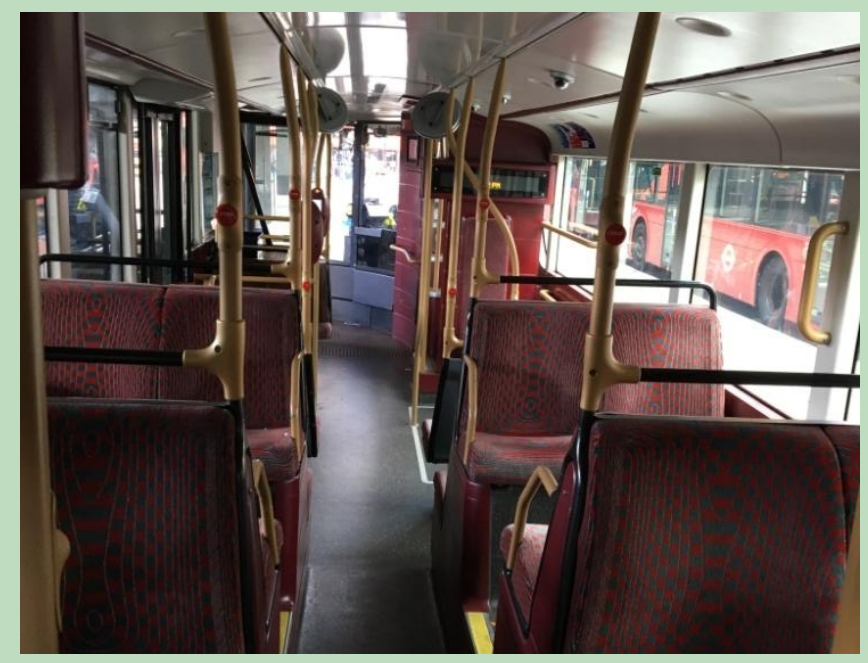

Figure 3. Interior design of new Routemaster (Source: Authors)

"I reckon there are six designs of buses on just one route, with seats, poles, bells, wheelchair bays and doors at different places - it makes finding your way around the bus really hard. They're not the same as the last bus you use, and you're trying to work all these out while standing on a platform that is moving in three-dimensions, that is inherently dangerous and unstable."

(Interviewee U, Male, 27/6/2018)

"The interior designs make it harder to find a seat."

(Interviewee W, Male, 29/6/2018)

"Different positions of the pole on the bus can be dangerous."

(Interviewee F, Female, 10/6/2018)

While operational needs make it impractical to require operators to deploy a single identical fleet, they should nonetheless make a real effort to limit the types of fleet used 
within each route, or make it easier for VIP to understand which type of vehicle they are on. This would help regular users to recognise the interior design of their bus and become familiar with the locations of seats and poles, and thus would make them feel safer in the onboard environment.

\subsection{Real-time information (RTI)}

Service reliability relates to overall experience and can be illustrated by RTI (Fadaei and Cats, 2016). It is common to see display panels at railway stations and bus stops containing the RTI about services (Figure 4). Many VIP are aware of such facilities, yet they cannot benefit from them as they are currently designed.

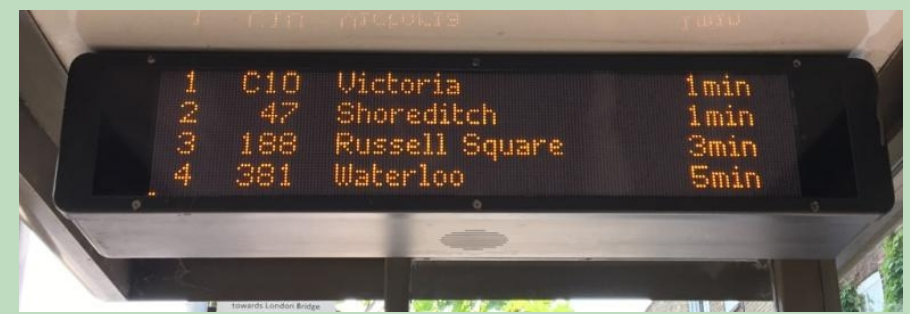

Figure 4. RTI display panel at Bermondsey Station Bus Stop A (Source: Authors)

"RTI could be useful. I know it is there, but I cannot see it."

(Interview A, Male, 30/5/2018)

Consulting service timetables is a common method for VIP to judge whether they are taking the correct bus service (Hine and Mitchell, 2001; Gallagher et al., 2011; Hara et al., 2015), but it is not always reliable because of unpredictable traffic conditions. As a result of technological advancements, most buses are now equipped with GPS, which records the location of the vehicle, and the RTI can be shown on the stations' display panels. However, that information is still not readily available to VIP because it is mainly presented in visual format that is not accompanied by audio announcements. Even for those with residual eyesight, reading information on the stations' illuminated panels is difficult and challenging because they are placed above eye level and are difficult to get close to. Hence, despite the availability of RTI, VIP can seldom use it, which seems like a huge waste of resource.

Currently, some VIP use third-party Apps on smartphones to access the RTI for buses, but these forms of RTI access are not without problems. Not all Apps are compatible with the voice-over ${ }^{4}$ function, so access to RTI is rare and some VIP still simply rely on other people to give them RTI. This of course does not always work, for instance if there are no other people around or if they are unapproachable.

In London, Underground lines with multiple destinations use the same track ${ }^{5}$. Observations reveal that audio announcements at the platforms only give the destination of the first train. If VIP are not assisted, they are unable to discern which train to board because the order of trains is shown only on the visual display panel (Figure 5).

\footnotetext{
${ }^{4}$ Assistive technology with built-in screen reader that describes aloud what appears on the screen.

${ }^{5}$ Central Line: 2 branches for Westbound and 2 branches for Eastbound; District Line: 3 branches for Westbound and 2 branches for Eastbound; Metropolitan Line: 4 branches for Westbound; Northern Line: 2 branches through Central London and 3 branches in the North; Piccadilly Line: 2 branches for Westbound.
} 


\section{Ealing Drod Nuy \\ 2 west puistip \\ Swhite Citu}

Figure 5. RTI display panel for Central Line Westbound service (Source: Authors)

"It would be handy to find the correct service with RTI announcements."

(Interviewee L, Female, 15/6/2018)

Most interviewees believed that, if RTI were available to them, it would be helpful for their journey. This finding was also consistent with the literature on the positive impacts of RTI on sighted passengers' experiences by shortening waiting time and alleviating stress during the wait (Zhang, Shen and Clifton, 2008; Watkins et al., 2011; Brakewood, Barbeau and Watkins, 2014). According to the few experiences that VIP shared about using RTI for bus journeys, the wider availability of RTI could help to achieve a similar journey experience to that of non-disabled passengers.

\subsection{Audio announcements}

London is renowned for the "talking" buses, as is the rail network across the UK almost all public transport services are equipped with audio announcements. Audio information not only reminds passengers where their vehicle is, but, as the major source of information for VIP, it is crucial to them. It already shapes the mode choice of VIP, even before its availability widens.

"I only started using buses in London after there was audio. It was impossible to travel on the bus when you had no clue where it was."

(Interviewee U, Male, 27/6/2018)

Research findings confirming that audio announcements play a crucial role in helping VIP to be prepared to alight from the vehicle are consistent with previous literature (Golledge, Marston and Costanzo, 1997; ECMT, 2006; RNIB Cymru, 2014; Smith, 2014). It is also compulsory for all rail vehicles to be equipped with audio announcements as specified in The Rail Vehicle Accessibility Regulations 2010 (DfT, 2010).

"It is very useful that the station name is mentioned twice, so I can be prepared to get off."

(Interviewee T, Female, 27/6/2018)

Announcing the stations twice on the Underground helps VIP locate where they are. During a journey, they often have to focus on the audio announcements in order to know when to alight. However, that can be challenging in the noisy onboard environment, which can be due either to crowding or to noise from the track in the tunnel.

"I almost miss the station because it's too noisy inside the Tube. When I heard the announcement at the station I had to jump off the seat." 
Hence, announcing the stations twice functions as insurance for VIP who may miss one of the announcements, especially in a noisy carriage. This can reduce their anxiety about getting lost and thereby can enhance their experience.

On the Circle, District, Hammersmith and City and Metropolitan Lines, the station name is announced three times, which appears to be appealing to VIP. However, they voiced concerns about the order of presentation within the announcement. A typical announcement made while passengers are waiting is as follows:

"This is Barbican. The next station is Moorgate. (Pause)

This is a Metropolitan Line Train to Aldgate."

By the time the line is announced, the train doors are usually closing. This breaches the Rail Vehicle Accessibility (Non-Interoperable Rail System) Regulations 2010, which state that the destination and the next stop must be announced when the vehicle is stopped at a station (Department for Transport, 2010). The operator has applied for an exemption, claiming that complying with the regulation would increase idling time at the station and reduce service frequency (Department for Transport, 2017). With multiple Underground lines running on the same track ${ }^{6}$, the first train may not necessarily lead to the desired destination. This can make it hard for VIP to board the correct service, because they cannot see the destination displayed on the train.

"It can be confusing if VIP are travelling alone and only realise they're on the wrong train when the doors are closing, especially at the station before the lines diverge."

(Interviewee S, Male, 26/6/2018)

Some VIP highlight that audio announcements made at the platform do inform them which destination an approaching train is bound for, but the audio volume may not always be high enough, particularly in a noisy environment. Hence, VIP often have to rely on the announcement on board to ensure they are on the right one. Uncertainty about travel information makes the journey experience more stressful for VIP.

There is no doubt that audio announcements are beneficial to VIP, and the situation can be further improved by considering the comments made by VIP, who requested that useful content be presented in the acoustic information. In addition, having multiple audio outlets equally spaced within the carriage would make it easier for VIP to hear the information, even in a crowded environment.

\subsection{Staff assistance}

"Staff assistance is the biggest concern of the journey."

(Interviewee A, Male, 30/5/2018)

\footnotetext{
${ }^{6}$ Hammersmith to Baker Street: Circle Line, Hammersmith and City Line; Baker Street to Liverpool Street: Circle Line, Hammersmith and City Line, Metropolitan Line; Aldgate East and Barking: District Line, Hammersmith and City Line.
} 
"It's important to have staff to help me navigate around especially at an unfamiliar station."

All the interviewees mentioned issues related to staff assistance and attitudes, thus revealing the staff's relevance to VIP's journey experiences. Availability of staff assistance prior to boarding was the most common reason given for choosing the Underground over buses (buses only have staff at large terminals) and National Rail (which requires the assistance to be pre-booked). In previous studies, it was assumed that staff assistance was satisfactory to the experience. In addition, preference for the Underground is contradictory to previous research in the UK regarding the mode choice of disabled passengers (Jones and Jain, 2006; Pavey et al., 2009). This discrepancy can be explained by the heterogeneity in the needs of disabled passengers, as VIP represent only one class of people on the disability spectrum (Gant, 1992).

TfL operates a "turn-up-and-go" system for using staff assistance, so passengers do not have to book assistance in advance. According to most of the interviewees, the waiting time varies between Underground stations. At busy or unstaffed stations, VIP may have difficulty getting assistance. During an off-peak hour, VIP were observed to have no difficulty finding staff at the wider ticket gate. However, more than 10 minutes elapsed before the VIP could be escorted to the platform because the staff at the origin station had to call ahead to the interchange station and the final destination to arrange everything before assisting the VIP to board the train. In another observation, the VIP had to rely on others to alert the staff, who were busy helping other passengers and could not see the VIP waiting at the wider ticket gate. Such situations are not ideal for VIP, because they have to set aside extra travel time just for making logistical arrangements.

"I was stranded because part of the communication chain was broken and there's no assistance at the intermediate station."

(Interviewee I, Female, 13/6/2018)

"I want smoother arrangements."

(Interviewee K, Male, 14/6/2018)

Thus, although staff assistance on the Underground is comprehensive in that it arranges for staff to put the VIP on the train and to pick them up at the platform of their destination, this may not actually translate into an effective service for VIP. Indeed, some VIP only require assistance from the ticket gate to the train and are independent in alighting, but currently there is no option for partial service. VIP still have to wait for arrangements for the whole chain to be made before they are able to embark. This long waiting time can detract from their journey experience and make accessing activities too lengthy an ordeal.

"I'm happy to be just put on a train and get off myself independently. Even when you tell them you're fine, they have to ring ahead to other stations and it takes time. I am human; I will sometimes be late too. I should be allowed to decide for myself when to get off. They're undermining passengers, making the experience unpleasant."

(Interviewee T, Female, 27/6/2018) 
"After waiting for some time, I decided to travel on my own. However, the staff refused me entry because they couldn't provide assistance at that time, although I told them I could do it by myself."

(Interviewee S, Male, 26/6/2018)

On the other hand, participants were generally negative towards staff assistance from the National Rail service, which requires passengers to pre-book assistance at least 24 hours before their journey, reducing the flexibility available to VIP in making their journey. This was a particularly common complaint from VIP who travel regularly.

"I think it's actually wrong that people with a disability should book assistance because that limits your freedom. I cannot always predict how long the meeting will take. When I want to go home, I want to go home, and not wait until the time (of the pre-booked assistance). It's dehumanising, so I never book assistance."

(Interviewee D, Male, 7/6/2018)

"I prefer to travel in my own time and in my own space. So I don't usually use assistance for this reason."

(Interviewee N, Female, 18/6/2018)

Throughout the interviews, the VIP often compared the "turn-up-and-go" service available on the Underground with the pre-booked assistance for the National Rail service, and reported the issue of equality of passenger rights. They expressed a desire for "turn-up-and-go" to be extended to all railway services in London, stating that it would improve their journey experience. Although it is hard to ensure sufficient staffing at every railway station to provide VIP with instant support, stringent efforts should be made to enable the same flexibility of travel on public transport as for non-disabled passengers.

\subsection{Freedom pass (FP)}

All the interviewees were positive about the FP and found it very useful. A range of positive impacts was discussed, adding to the literature on encouraging more trips (Metz, 2003; Mackett, 2013) and the symbolic entitlement to free travel for older people (Jones et al., 2013).

First, the FP gives VIP huge savings in travel costs. In monetary terms, it addresses certain socio-economic issues relating to the disadvantaged by compensating them for the high transport costs of travelling around. As Joseph and Robinson (2012) illustrated, transport is a barrier to job-seeking for VIP. By removing the cost barrier, VIP are not restricted to employment within a specific proximity.

\section{"It's already hard for VIP to get a job, so FP means a lot for the budget." (Interviewee C, Female, 7/6/2018)}

Many interviewees appreciated the symbolism of "freedom" associated with the FP. For a lot of VIP, when they lost their vision it became difficult for them to take even the first step beyond their home. However, the FP gives them the opportunity and the 
encouragement to reach out further. Hence the symbolic meaning of the FP to VIP extends beyond being entitled to benefits.

"It encourages me to travel as I have my freedom back."

(Interviewee C, Female, 7/6/2018)

"I travel a lot more now that I have one, as it gives me freedom."

(Interviewee T, Female, 27/6/2018)

"I'm having the freedom to choose more appropriate routes that could have been more expensive."

(Interviewee H, Male, 13/6/2018)

The FP enables VIP to take part in activities, and this affects their well-being. They can attend activities without worrying about the transport cost, thus removing a major barrier to participation. This is consistent with the literature, which states that mobility and well-being are mutually influential for older people (Ziegler and Schwanen, 2011; Nordbakke and Schwanen, 2015). It also confirms a previous study that fare exemptions on buses engender the well-being of young people in London (Jones et al., 2012).

"Before having FP, I was less able to do things. It enables me to take part in sports activities."

(Interviewee R, Female, 25/6/2018)

"It's very useful because it gives you the opportunity, as someone with disability, to go out, to go to a job, and you're not just stuck in your house."

(Interviewee G, Female, 11/6/2018)

"It's an encouragement to go to places because you can exercise."

(Interviewee W, Male, 29/6/2018)

Engaging in activities enables VIP to socialise with others, thereby addressing potential psychological issues arising from their disability. This confirms previous claims that VIP are socially disadvantaged due to accessibility issues (Lucas, 2012). Through London's good public transport network, and with the FP addressing cost issues, a more inclusive environment is created.

"FP made it more tempting to go out to meet new people, to try new things, to see new places."

(Interviewee O, Male, 18/6/2018)

"One of the great problems with sight loss is depression caused by isolation. The more you go out, FP in a sense can achieve that."

(Interviewee E, Male, 8/6/2018)

Another psychological issue addressed by the FP is anxiety about going out. Gallagher et al. (2011) outlined that VIP feel stressed about missing their stops when they travel alone. Comments from VIP revealed that having a FP alleviates their anxiety and worries about going the wrong way. Hence, the FP gives them the courage to try travelling solo on public transport. 
"I can take a rehearsal journey for an important appointment to figure out the way to get there without worrying about the cost."

(Interviewee F, Female, 10/6/2018)

"When I get lost or use the wrong route, FP compensates the burden."

(Interviewee J, Female, 13/6/2018)

In a wider sense, the FP contributes to transport sustainability goals by encouraging people to use public transport instead of a taxi or private vehicle. Public transport is sustainable, in terms of the transport hierarchy, because it has relatively low perpassenger emissions compared with private modes. Such a phenomenon has not been explored in previous studies on the impact of concessionary travel among older people. While some older people are still able to drive, VIP cannot, and hence they depend on public transport to get around.

"FP is encouraging for giving public transport a try."

(Interviewee M, Male, 18/6/2018)

"Instead of taking a taxi, sometimes I take public transport."

(Interviewee D, Male, 7/6/2018)

To summarise, the FP is a very useful policy measure that delivers a tremendously positive impact for VIP when they use public transport. This should be continued in the future to enable VIP to reach out and be independent.

\section{Conclusions}

This study has examined the issue of VIP taking public transport in London. Through a qualitative approach of conducting in-depth interviews with 23 VIP, reflections on the journey experience were captured. The concerns and expectations identified were highlighted for further analysis. Journeys are generally much too difficult for VIP, even in a context where extensive public transport is available. Everyone has the right to access the transport system, and to participate in activities that improve their quality of life. Yet VIP often experience many difficulties on their journeys and these are overlooked by policymakers. Hence, they need to be much better understood and resolved.

Our findings show, firstly, that access to information is a major barrier to VIP. Although the availability of the Internet has improved people's access to information, VIP still face challenges in planning their trips because a single platform containing all the information they need does not yet exist. As a result, they have to switch between various information sources to plan a single trip. Second, having access to the Internet is not equivalent to being able to receive information updates, because they are not always in an accessible format at easy-to-reach places. Hence, we argue that VIP require improved access to information to help with journey experiences. VIP often rely on information produced by charities and other private organisations rather than the official sources. Finally, the interviews show that the lack of consistency across the TfL network poses a barrier to a smooth journey for VIP. For example, the absence of tactile paving on some platforms and the inconsistent interior designs of vehicles make VIP 
insecure and fearful about their personal safety.

Therefore, we argue that there is great scope for improvement in terms of accessible travel aids on public transport, based on the existing journey experience of VIP. The literature and research findings stress that RTI is important for a positive journey experience, yet it is rarely used by VIP because it is not delivered in formats accessible to them. The use of audio announcements on public transport is very beneficial to VIP's journey experience, based on the feedback from the interviewees, because it is the major source of information for them. However, information delivery could be further improved for a better experience by VIP. Moreover, staff assistance is a concern for VIP. Long waiting times and staff with an unhelpful attitude reduce the overall quality of the journey experience. TfL's 'turn-up-and-go' provision of assistance is welcomed by VIP because it increases their travel flexibility. These factors add to the findings from previous literature, which do not emphasise the travel experience relative to staff issues. The Freedom Pass (FP) is a critical aid to VIP, bringing a variety of positive impacts when using public transport. Apart from its symbolic entitlement, the scheme addresses the socio-economic issues of transport costs and personal well-being, and encourages VIP to actively venture out to different places.

As we can see, decisions on taking public transport are affected by the journey experience (Edvardsson, 1998). Our research found that both positive and negative journey experiences can influence future decision making concerning public transport. Moreover, the Equality Act 2010 states that VIP should be entitled to the same experience as that of non-disabled passengers. Hence, planners and policymakers should make greater efforts to improve public transport services in order to enhance the journey experiences of VIP. With the wider availability of smart technology, TfL should consider developing an integrated smartphone App for delivering travel information, ranging from journey planning and service status updates to RTI about buses and railway services. Technology can help enhance the experiences of VIP. Indeed, most information is readily available in visual formats, so the key will be to transform this into a format that is compatible with and presentable on smartphones, so that VIP can also access it.

Audio announcements and FP are some of the resources that are found to be useful and important for VIP who wish to travel independently around the city on public transport. With the threat of budget cuts, VIP are worried about the reduction in staff at stations, making it more difficult for them to seek assistance. It is crucial to understand that staff assistance is an inseparable part of the journey experience of VIP on public transport. We argue that the rights of VIP should not be affected by the financial operation of the national government. Hence, it is suggested that the transport authority consider carefully, in their reaction to cost-cutting needs, how to continue providing sufficient assistance to VIP.

Directions for future research arise from the findings of this study. First, similar studies could be replicated for other types of disabilities in an effort to understand those people's experiences and needs. There are some differences found relative to the previous literature, which has tended to address all types of disabilities - we have attempted to highlight the specific needs of VIP. Disabled people face differing challenges in using public transport and future work focusing on specific groups could offer further insights. In addition, in order to extend the study's findings, future research 
could investigate how technology could improve the journey experience of VIP. Currently, some participants already benefit from the use of smart technology, which is designed for smoother journey planning. Because this is continually advancing, technology is expected to have an even greater impact on the travel experiences and trip decisions of VIP in the future. Moreover, further research could examine how the different stakeholders in society define "accessibility". For instance, the Public Transport Accessibility Level (PTAL), used for measuring public transport in transport planning, refers to walking time, reliability of service, number of services available and level of service (TfL, 2015). A bus stop is considered to be accessible when ramps can be deployed for wheelchair and reduced mobility users (TfL, 2017). However, VIP view accessibility in terms of safety and removal of obstacles. Hence the different perspectives on accessibility may deserve further investigation. To overcome the limitation of the sampling used in this research, it is also suggested that future research could adopt other sampling methods in order to reach VIP whose access to information is more limited, in order to reflect the situation more accurately.

Specific provisions are made for disabled passengers on public transport, yet our findings suggest that many factors need improvement. These will help enhance access to independent travel on public transport and to activities in the city. Disabled people are a heterogeneous group with differing needs, and future policies and aids should address the particular needs of passengers, instead of attempting to address the wide spectrum of disabled persons with limited interventions. Although this study focussed on London, the results could also provide valuable insights for improving VIP's experience of public transport in cities internationally. If transport really is to be for everyone, then a detailed understanding of individual requirements needs to be developed - and the transport systems to be improved to match this heterogeneity.

\section{Acknowledgements}

Thanks to extensive comments from the reviewers, they have significantly improved the paper.

\section{References}

Aarhaug, J. and Elvebakk, B. (2015) The impact of universally accessible public transport - a before and after study. Transport Policy, 44, 143-150.

American Foundation for the Blind. (2015) Accessible Mass Transit. Why is Access to Mass Transit Important for People Who Are Blind or Visually Impaired? [online]. Available from: http://www.afb.org/info/living-with-vision-loss/getting-around/accessible-masstransit/235 [Accessed 3 May 2018].

Andre, P., Wilson, M., Owens, A. and Smith, D. (2007) Journey Planning Based on User Needs. Proceedings of the SIGCHI Conference on Human Factors in Computing Systems: $\mathrm{CHI}$ 2007, 2025-2030.

Azenkot, S. and Lee, N. (2013) Exploring the use of speech input by blind people on mobile devices. Proceedings of the 15th International ACM. 1-8

Azenkot, S., Prasain, S., Borning, A., Fortuna, E., Ladner, R. and Wobbrock, J. (2011) Enhancing Independence and Safety for Blind and Deaf-Blind Public Transit Riders. Proceedings of the ACM CHI Conference on Human Factors in Computing System: CHI 2011, 1-10.

Balachandran, W., Cecelja, F. and Ptasinski, P. (2003) A GPS based navigation aid for the blind. $17^{\text {th }}$ International Conference on Applied Electromagnetics and Communications.

Banister, D. and Bowling, A. (2004) Quality of life for the elderly: The transport dimension. Transport Policy, 11(2), 105-115. 
Bhowmick, A. and Shyamanta, M. (2017) An insight into assistive technology for the visually impaired and blind people: state-of-the-art and future trends. Journal on Multimodal User Interfaces, 11(2), 1-24

Brakewood, C., Barbeau, S. and Watkins, K. (2014) An experiment evaluating the impacts of real-time transit information on bus riders in Tampa, Florida. Transportation Research Part A: Policy and Practice, 69, 409-422.

Braun, V. and Clarke, V. (2006) Using thematic analysis in psychology. Qualitative Research in Psychology, 3(2), 77-101.

Bryman, A. (2008) Social Research Methods, $3^{\text {rd }}$ ed. Oxford: Oxford University Press.

Butcher, L. (2018) Access to transport for disabled people. London: House of Commons Library.

Cao, M. and Hickman, R. (2019a) Understanding travel and differential capabilities and functionings in Beijing. Transport Policy, 83, 46-56.

Cao, M. and Hickman, R. (2019b) Urban transport and social inequities in neighbourhoods near underground stations in Greater London. Transportation Planning and Technology, 42(5), 419-441.

Cao, M. and Hickman, R. (2020) Transport, Social Equity and Capabilities in East Beijing. In: Chen, C.-L., Pan, H., Shen, Q. and Wang, J. (eds.), Handbook on Transport and Urban Transformation in China. Cheltenham: Edward Elgar, 317-333.

Carreira, R., Patrício, L., Natal Jorge, R. and Magee, C. (2014) Understanding the travel experience and its impact on attitudes, emotions and loyalty towards the transportation provider-A quantitative study with mid-distance bus trips. Transport Policy, 31, 35-46.

Casey, H., Brady, N. and Guerin, S. (2013) 'Is Seeing Perceiving?' Exploring issues concerning access to public transport for people with sight loss. The British Journal of Visual Impairment, 31(3), 217-227.

Cheng, Y. (2010) Exploring passenger anxiety associated with train travel. Transportation, 37 (6), 875-896.

Church, A., Frost, M. and Sullivan, K. (2000) Transport and social exclusion in London. Transport Policy, 7(3), 195-205.

Clery, E., Kiss, Z., Taylor, E. and Gill, V. (2017) Disabled people's travel behaviour and attitudes to travel. London: Department for Transport.

Coffey, M., Coufopoulos, A. and Kinghorn, K. (2014) Barriers to employment for visually impaired women. International Journal of Workplace Health Management, 7(3), 171185.

Cook, C. (2014) How accessible are the public transport networks of Berlin and London?. World Transport Policy and Practice, 20(4), 43-58.

Currie, G., Richardson, T., Smyth, P., Vella-Brodrick, D., Hine, J., Lucas, K., Stanley, J., Morris, J., Kinnear, R. and Stanley, J. (2009) Investigating links between transport disadvantage, social exclusion and well-being in Melbourne - Preliminary Results. Transport Policy, 16(3), 97-105.

Delbosc, A. (2012) The role of well-being in transport policy. Transport Policy, 23, 25-33.

Department for Transport (DfT). (2010) The Rail Vehicle Accessibility (Non-Interoperable Rail System) Regulations 2010. [Online]. Available from: http://www.legislation.gov.uk/uksi/2010/432/pdfs/uksi_20100432_en.pdf [Accessed 25 July 2018].

Department for Transport (DfT). (2010) The Rail Vehicle Accessibility (Non-interoperable Rail System) Regulations 2010. [Online]. Available from http://www.legislation.gov.uk/uksi/2010/432/pdfs/uksi_20100432_en.pdf [Accessed 29 March 2020]

Department for Transport (DfT). (2017) Rail Vehicle Accessibility: Exemption Application S7 and S8 Stock. [Online]. Available from: https:/assets.publishing.service.gov.uk/government/uploads/system/uploads/attachme nt_data/file/620134/s7-s8-rvar-exemption-application.pdf [Accessed 25 July 2018].

Department for Transport (DfT). (1998) A New Deal for Transport: Better for Everyone. [Online]. 
http://webarchive.nationalarchives.gov.uk/+/http://www.dft.gov.uk/about/strategy/whit epapers/previous/anewdealfortransportbetterfo5695 [Accessed 22 February 2018].

Disabled Persons Transport Advisory Committee (DPTAC). (2006) Attitudes of Disabled People to Public Transport. London: Disabled Persons Transport Advisory Committee.

Drabble, L., Trocki, K., Salcedo, B., Walker, P. and Korcha, R. (2016) Conducting qualitative interviews by telephone: Lessons learned from a study of alcohol use among sexual minority heterosexual women. Qualitative Social Work, 15(1), 118-133.

Eboli, L. and Mazzulla, G. (2008) A stated preference experiment for measuring service quality in public transport. Transportation Planning and Technology, 31(5), 509-523.

Edvardsson, B. (1998) Causes of customer dissatisfaction - studies of public transport by the critical-incident method. Managing Service Quality: An International Journal,. 8(3), pp 189-197.

European Conference of Ministers of Transport (ECMT). (2006) Improving Transport Accessibility for All. France: OECD Publications Service

European Parliament. (2018) Passenger Rights. [Online]. Available from: http://www.europarl.europa.eu/atyourservice/en/displayFtu.html?ftuId=FTU_2.2.3.ht mlhttp://www.europarl.europa.eu/atyourservice/en/displayFtu.html?ftuId=FTU_2.2.3. html [Accessed 4 June 2018].

Fadaei, M. and Cats, O. (2016) Evaluation the impacts and benefits of public transport design and operational measures. Transport Policy, 48, 105-116.

Gallagher, B., Hart, P., O’Brien, C., Stevenson, M. and Jackson, A. (2011) Mobility and access to transport issues as experienced by people with vision impairment living in urban and rural Ireland. Disability and Rehabilitation, 33(12), 979-988.

Gant, R. (1992) Transport for the disabled. Geography, 77(1), 88-91.

Goertz, Y., van Lierop, B., Houkes, I. and Nijhuis, F. (2010) Factors related to the employment of visually impaired persons: A systematic literature review. Journal of Visual Impairment and Blindness, 104 (7), 404-418.

Golledge, R. and Marston, J. (1999) Towards an Accessible City: Removing Functional Barriers to Independent Travel for Blind and Vision-Impaired Residents and Visitors. UC Berkeley: California Partners for Advanced Transportation Technology.

Golledge, R., Marston, J. and Costanzo, C. (1997) Attitudes of visually impaired persons towards the use of public transportation. Journal of Visual Impairment \&and Blindness, 91(5), 446-459.

Gonzalez, P., Weinstein, J., Barbeau, S., Labrador, M., Winters, P., Georggi, N. and Perez, R. (2010) Automating mode detection for travel behaviour analysis by using global positioning systems-enabled mobile phones and neural networks. IET Intelligent Transport System, 4(1), 37-49.

Greater London Authority (GLA). (2018) Mayor's Transport Strategy. [online]. Available from: https://www.london.gov.uk/sites/default/files/mayors-transport-strategy-2018.pdf [Accessed 12 July 2020].

Guide Dogs. (2018) Which places have talking buses? [online]. Available from: https://www.guidedogs.org.uk/how-you-can-help/campaigning/talking-buses/whichplaces-have-talking-buses [Accessed 4 June 2018].

Gulati, R. (2011) GPS based voice alert system for the blind. International Journal of Scientific and Engineering Research, 2(1), 44-48

Hallgrimsdottir, B., Wennberg, H., Svensson, H., Agneta, S. (2016) Implementation of accessibility policy in municipal transport planning - Progression and regression in Sweden between 2004 and 2014. Transport Policy, 49, 196-205.

Hara, K., Azenkot, S., Campbell, M., Bennett, C., Le, V., Pannella, S., Moore, R., Minckler, $\mathrm{K}$., Ng, R. and Forehlich, J. (2015) Improving public transit accessibility for blind riders by crowdsourcing bus stop landmark locations with google street view: An extended analysis. ACM Transactions on Accessible Computing, 6(2), 1-23.

Hersh M.A. (2010) 2010. The Design and Evaluation of Assistive Technology Products and Devices Part 1: Design. International Encyclopedia of Rehabilitation. CIRRIE; Buffalo, NY, USA. 
Hickman, R., Chen, C.-L., Chow, A. and Saxena, S. (2015) Improving interchanges in China: the experiential phenomenon. Journal of Transport Geography, 42, 175-186.

Hine, J. and Mitchell, F. (2001) Better for everyone? Travel experiences and transport exclusion. Urban Studies, 38(2), 319-332.

Hine, J. and Scott, J. (2000) Seamless, accessible travel: Users' views of the public transport journey and interchange. Transport Policy, 7, 217-226.

Hong Kong Social Workers' General Union (HKSWGU). (2016) The Experience of People with Visual Impairment Using Public Transportation Systems in Hong Kong. Hong Kong: HKSWGU.

Johnson, R., Shaw, J., Berding, J., Gather, M. and Rebstock, M. (2017) European national government approaches to older people's transport system needs. Transport Policy, 59, 17-27.

Jones, A., Goodman, A., Roberts, H., Steinbach, R. and Green, J. (2013) Entitlement to concessionary public transport and well-being: A qualitative study of young and old citizens in London, UK. Social Science and \& Medicine, 91, 202-209.

Jones, A., Steinbach, R., Roberts, H., Goodman, A. and Green, J. (2012) Rethinking passive transport: Bus fare exemptions and young people's well-being. Health and Place, 18(3), 605-612.

Jones, T. and Jain, J. (2006) Examining the experiences of sight-impaired travellers: The next station stop?. The British Journal of Visual Impairment, 24(3), 141-144.

Joseph, M. and Robinson, M. (2012) Vocational experiences of college-educated individuals with visual impairments. Journal of Applied Rehabilitation Counseling. 43(4), 21-29.

Karekla, X., Fujiyama, T. and Tyler, N. (2011) Evaluating accessibility enhancement to public transport including indirect as well as direct benefits. Research in Transportation Business and Management, 2, 92-100.

Kenyon, S., Lyons, G. and Rafferty, J. (2002) Transport and social exclusion: Investigating the possibility of promoting inclusion through virtual mobility. Journal of Transport Geography, 10(3), 207-219.

Legislation.gov.uk. (1995) Disability Discrimination Act 1995. [online]. Available from: http://www.legislation.gov.uk/ukpga/1995/50/contents [Accessed 1 July 2020].

Legislation.gov.uk. (2005) Disability Discrimination Act 2005. [online]. Available from: http://www.legislation.gov.uk/ukpga/2005/13/crossheading/transport [Accessed 1 July 2020].

Legislation.gov.uk. (2010) Equality Act 2010. [online]. Available from: http://www.legislation.gov.uk/ukpga/2010/15/contents [Accessed 4 July 2020].

Local Government Association. (2017) Get in on the Act: Bus Services Act 2017. London: Local Government Association.

London Assembly. (2016) Leading the way - Travelling with a sensory impairment in London. London: Greater London Authority.

London Councils. (2018a) Disabled Persons Freedom Pass. [online]. Available from: https://www.londoncouncils.gov.uk/services/freedom-pass/disabled-persons-freedompass [Accessed 4 June 2018].

London Councils. (2018b) Taxi Card. [online]. Available from: https://www.londoncouncils.gov.uk/services/taxicard [Accessed 6 July 2018].

Lucas, K. (2012) Transport and social exclusion: Where are we now?. Transport Policy, 20, $105-113$.

Mackett, R. (2013) Impact of concessionary bus travel on the well-being of older and disabled people. Journal of the Transportation Research Board, 2352, 114-119.

Mackett, R. (2014) Has the policy of concessionary bus travel for old people in Britain been successful? Case Studies on Transport Policy, 2(2), 81-88.

Marion A.H. and Michael A.J. (2008) Assistive technology for Visually-impaired and Blind People. London: Springer.

Markiewicz, M. and Skomorowski, M. (2010) Public Transport Information System for Visually Impaired and Blind People. In Mikulski, J. (ed.) Transport System Telematics - 10th Conference, Katowice - Ustron, Poland, October 20-23, 2010, 271-277. 
Marston, J. and Church, R. (2005) A relative access measure to identify barriers to efficient transit use by persons with visual impairments. Disability and Rehabilitation, 27(13), 769-779.

Marston, J. and Golledge, R. (1998) Improving Transit Access for the Blind and Vision Impaired. Intellimotion, 7(2), 4-5 and 11.

Marston, J. and Golledge, R. (2003) The hidden demand for participation in activities and travel by persons who are visually impaired. Journal of Visual Impairment and Blindness, $97(8), 475-484$.

Marston, J., Golledge, R. and Costanzo, M. (1997) Investigating travel behavior of non-driving blind and vision impaired people: The role of public transit. The Professional Geographer, 49(2), 236-245.

Matthews, B. (2002) The Disability Discrimination Act and Developments in Accessible Public Transport in the UK. World Transport Policy and Practice, 8(2), 42-49.

Metz, D. (2003) Transport policy for an ageing population. Transport Reviews, 23(4), 375-386.

Montarzino, A., Robertson, B., Aspinall, P., Ambrecht, A., Findlay, C., Hine, J. and Dhillon, B. (2007) The Impact of Mobility and Public Transport on the Independence of Visually Impaired People. Visual Impairment Research, 9(2-3), 67-82.

Nordbakke, S. (2013) Capabilities for mobility among urban older women: Barriers, strategies and options. Journal of Transport Geography, 26, 166-174.

Nordbakke, S. and Schwanen, T. (2015) Transport, unmet activity needs and well-being in later life: Exploring the links. Transportation, 42(6), 1129-1151.

Oliver, M. (1983) Social Work with Disabled People. Basingstoke: Macmillans.

Pavey, S., Dodgson, A., Douglas, G. and Clements, B. (2009) Travel, Transport and Mobility of people who are blind and partially sighted in the UK. Birmingham: University of Birmingham.

Quinones, P., Greene, T., Yang, R. and Newman, M. (2011) Supporting Visually Impaired Navigation: A Needs-finding Study. Proceeding of the ACM CHI Conference on Human Factors in Computing Systems: CHI 2011, 1645-1650.

Rica. (2015) Rica Passenger Assist longitudinal study - Year 1 report. [Online]. https://www.visionuk.org.uk/wp-content/uploads/Rica-Passenger-Assist-LongitudinalStudy-Year-1-Summary-Final.pdf [Assessed 22 March 2020]

Rizzo, JR., Conti, K., Thomas, T., Hudson, T., Emerson, R. and Kim, DS. (2018) A new primary mobility tool for the visually impaired: A white cane - adaptive mobility device hybrid. Assistive Technology, 30(5), 219-225.

Rodrigue, J., Comtois, C. and Slack, B. 2013. The Geography of Transport Systems, $3^{\text {rd }}$ ed. London: Routledge.

Royal National Institute of Blind People (RNIB) Cymru. (2014) Get on board - How to make bus travel better for people with sight loss. Cardiff: RNIB Cymru.

Royal National Institute of Blind People (RNIB). (2012) Stop for me, speak to me - Catching a bus should not be a sight test. London: Royal National Institute of Blind People.

Royal National Institute of Blind People (RNIB). (2014) Consultation response. [Online]. Available from: http://www.cpa.org.uk/cpa-lga-evidence/RNIB/RNIBCentre_for_Policy_on_Ageing_consultation_Nov_2014.pdf [Accessed 21 May 2018].

Royal National Institute of Blind People (RNIB). (2018) Key information and statistics on sight loss in the UK. [Online]. Available from: http://www.rnib.org.uk/professionals/knowledge-and-research-hub/key-informationand-statistics [Accessed 22 February 2018].

Saleh, G. (2004) Consent of the blind and visually impaired: A time to change practice. British Journal of Ophthalmology, 88, 310-311.

Sammer, G., Uhlmann, T., Unbehaun, W., Millonig, A., Mandl, B., Dangschat, J. and Mayr, R. (2012) Identification of Mobility-Impaired Persons and Analysis of Their Travel Behavior and Needs. Journal of Transportation Research Board, 2320, 46-54.

Schmocker, J., Quddus, M., Noland, R and Bell, M. (2008) Mode choice of older and disabled people: A case study of shopping trips in London. Journal of Transport Geography, 16(4), 257-267. 
Schmocker, J., Quddus, M., Noland, R. and Bell, M. (2005) Estimating Trip Generation of Elderly and Disabled People. Journal of Transportation Research Record, 1924, 9-18.

Schreder, G., Siebenhandl, K., Mayr, E. and Smuc, M. 2012. The Ticket Machine Challenge: Social Inclusion by Barrier-free Ticket Vending Machines. In: Loos E.F., Haddon L., Mante-Meijer E. (eds.) Generational Use of New Media, Surrey: Ashgate Publishing Limited, 2012, 129-148.

Shiau, T. and Huang, W. (2014) User perspective of age-friendly transportation: A case study of Taipei City. Transport Policy, 36, 184-191.

Smith, R. (2014) Destination Unknown: An investigation into bus passenger experiences. Reading: Guide Dogs.

Soltani, S., Sham, M., Awang, M. and Yaman, R. (2012) Accessibility for Disabled in Public Transportation Terminal. Procedia - Social and Behavioral Sciences, 35, 89-96.

Stradling, S., Carreno, M., Rye, T. and Noble, A. (2007) Passenger perceptions and the ideal urban bus journey experience. Transport Policy, 14(4), 283-292.

The Institution of Engineering and Technology (IET) and Intelligent Transport System United Kingdom (ITS-UK). (2015) Meeting the needs of older and disabled travellers. [Online]. Available from https://www.theiet.org/media/3424/age-pop.pdf [Assessed 22 March 2020]

The International Association of Public Transport (UITP). (2016) Accessibility Guide. [Online]. Available from: http://www.uitp.org/sites/default/files/cck-focus-papersfiles/Accessibility\%20Guide_UITP-IRU-

EDF_2016.pdf.pdfhttp://www.uitp.org/sites/default/files/cck-focus-papersfiles/Accessibility\%20Guide_UITP-IRU-EDF_2016.pdf.pdf [Accessed 10 May 2018]

Transport for All. (2018) Accessible Transport in London. [online]. Available from: $\mathrm{http} / / / \mathrm{www}$.transportforall.org.uk/http://www.transportforall.org.uk/ [accessed $23 \mathrm{July}$ 2018].

Transport for London (TfL). (2012) Understanding the travel needs of London's diverse communities of Disabled People. London: Transport for London.

Transport for London (TfL). (2015) Assessing transport connectivity in London. London: Transport for London.

Transport for London (TfL). (2016) Travel in London Report 9. London: Transport for London.

Transport for London (TfL). (2017) Accessible Bus Stop Design Guidance. London: Transport for London.

Transport for London (TfL). (2018a) Transport Accessibility. [Online]. Available from: https://ffl.gov.uk/transport-accessibility/people-with-sight-or-hearing-

losshttps://tfl.gov.uk/transport-accessibility/people-with-sight-or-hearing-loss [Accessed 4 June 2018].

Transport for London (TfL). (2018b) Ways to pay. [Online]. Available from: https://tfl.gov.uk/fares-and-payments/ways-to-payhttps://tfl.gov.uk/fares-andpayments/ways-to-pay [Accessed 25 May 2018].

Transport for London (TfL). (n.d.) Accessible travel in London. London: Transport for London.

Transport Research Laboratory (TRL) Limited. (2004) Enhancing the mobility of disabled people: Guidelines for Practitioners. Berkshire: TRL Limited.

Urry, J. (2003) Social networks, travel and talk. British Journal of Sociology, 54(2), 155-175.

Verbich, D. and El-Geneidy, A. (2016) The pursuit of satisfaction: Variation in satisfaction with bus transit service among riders with encumbrances and riders with disabilities using a large-scale survey from London, UK. Transport Policy, 47, 64-71.

Wardman, M., Hine, J. and Stradling, S. (2001) Interchange and Travel Choice: Volume 2. Edinburg: Scottish Executive Central Research Unit.

Watkins, K., Ferris, B., Borning, A., Rutherford, G. and Layton, D. (2011) Where is My Bus? Impact of mobile real-time information on the perceived and actual wait time of transit riders. Transportation Research Part A: Policy and Practice, 45(8), 839-848.

Warnath, C. and Seyfarth, G. (1982) Guide dogs: Mobility tool and social bridge to the sighted world. Journal of Rehabilitation, 48(2), 58-61. 
White, J. (2013) Road to Nowhere - An investigation into the problems faced by bus passengers who are blind or partially sighted and the isolation caused. Reading: Guide Dogs.

Wong, R.C.P., Szeto, W.Y., Yang, L., Li, Y.C., Wong, S.C. (2018) Public transport policy measures for improving elderly mobility. Transport Policy, 63, 73-79.

Zhang, F., Shen, Q. and Clifton, K. (2008) Examination of traveller responses to real-time information about bus arrivals using panel data. Journal of the Transportation Research Board, 2082, 107-115.

Ziegler, F. and Schwanen, T. (2011) 'I like to go out to be energised by different people': An exploratory analysis of mobility and well-being in later life. Ageing and Society, 31(5), 758-781. 


\section{Appendix 1 Semi-structured Interview Question List}

\section{Question}

1) Where do you get information for route planning?

2) What criteria would you use to choose the route?

3) How would you comment on the ease of seeking staff assistance upon arrival at a station?

4) How important is it to know Real Time Information about public transport services?

5) What are the difficulties in boarding and alighting the vehicle?

6) What are the difficulties associated with different design and layout of vehicles?

7) How do you find out about the audio announcements on board?

8) What factors have you considered in rating your journey experience?

9) What are your expectations of infrastructure aids and support at stations?

10) What are the barriers to accessing information on accessible travel for disabled passengers?

11) What impacts does the Freedom Pass have on your life? 